\title{
Oral Health Disparities: Review
}

\author{
Dr. Pramod Yadav ${ }^{1}$, Dr. Bakshish Kaur ${ }^{2}$, Dr. Ruchi Srivastava ${ }^{3}$, \\ Dr. Sumedha Srivastava ${ }^{4}$ \\ ${ }^{1}$ (Public Health Dentistry, K.D.Dental College \&Hospital/Agra University, India) \\ ${ }^{2}$ (Prosthodontics, Peoples College of Dental Sciences/Peoples University, India) \\ ${ }^{3}$ (Periodontics, Saraswati Dental College, Lucknow/Dr.RML Avadh University, India) \\ ${ }^{4}$ (Periodontics Peoples College of Dental Sciences/Peoples University, India)
}

\begin{abstract}
This review considered inequalities affecting oral health. Oral health inequity-inequitable access to oral health services contributes to the health inequity of the population and further exasperates the socioeconomic inequity. This paper attempts to elaborate the nature of oral health inequity in India, by exploring the process and trajectories of oral health inequity. Despite vast improvement in global oral health, problems still persist in many communities and population around the world, particularly among the under privileged in both developed and developing countries. Poor oral health has a substantial impact on quality of life, with poor oral health-related quality of life, in turn, having a substantial impact on daily performance and general life satisfaction. Barriers to oral health care include illiteracy, financial constraints, cultural perceptions, lack of awareness, inequitable distribution of dental manpower and inaccessibility to services as seen in most parts of our country. Systematic differences in the dental practices attended were evident, as a function of the person's race and income, differences that are associated with social disparities in oral health. So these factors must be addressed to improve the oral health, and overall the general wellbeing, it gives a clear focus to health policy and promotes the monitoring of quantitative changes over time in inequalities in oral health, which is essential to assess the effects of health policy interventions.
\end{abstract}

Keywords: dental caries, India, inequity, oral health, public health.

\section{Introduction}

Despite great achievements in the oral health of populations globally, problems still remain in many communities around the world - particularly among underprivileged groups in developed and developing countries. Dental caries and periodontal diseases have historically been considered the most important global oral health burdens. At present, the distribution and severity of oral diseases vary in different parts of the world and within the same country or region. The significant role of socio-behavioral and environmental factors in oral disease and health is demonstrated in a large number of epidemiological surveys. ${ }^{1}$

Inequalities and their relation to living conditions are now in the mainstream of public health thinking. In Latin America, the Pan American Health Organization stated the growing impact on health and overall wellbeing of disparities associated with socioeconomic, gender and ethnic macro determinants. ${ }^{2}$

These considerations underline the importance of quantitative studies addressing inequalities of the need for oral health status and access to services in the Indian Context. "In the beginning, there was desire which was the first seed of mind," says Rig-Veda, which probably is the earliest piece of literature known to mankind. This desire for a healthy family, healthy society and a healthy country drives individuals and governments alike. The government is supposed to create settings that will provide equal opportunity for an individual to fulfil these desires. There is an undisputed association between this social equality, social integration and health. ${ }^{3}$

When applied to Indian context these social phenomenon translate into millions of lives that perish due to a lack of socio-economic equality. Since the emergence of free India in 1947, economic egalitarianism dominated the economic policies. Socialism and government-centered economic policies were favoured over the profit-making. Private enterprise and capitalism. Slow and unequal social mobilization in various parts of India led to an uneven economic growth. Caste and social polarization, literacy and educational levels, natural resources, levels of corruption and role of political Leadership has resulted in some Indian states doing better than others on the economic front. This basic inequality was magnified by the rapid but unequal economic growth that India has witnessed in the last two decades. ${ }^{4}$

\section{Oral health burden in India}

The oro-dental diseases are emerging as considerable public health problems in India. Oral problems are not only causing pain, agony, functional and aesthetic 
Problems but also lead to loss of working man-hours. According to estimates, about $50 \%$ of schoolchildren are suffering from Dental caries and more than $90 \%$ of adults are having periodontal diseases. The use of tobacco products, smoking or smokeless form, are widely prevalent in our country. Hence, oral precancers and cancers are emerging as major threat to younger people and are increasing to alarming proportion in India.

Though gains of public education and motivation appear impressive at the macro level, at the subpopulation level the changes in most parts of country are confined to middle and high socio-economic groups and the decline in risk factors is either not present or very small in the low socio-economic status individuals. This has given rise to major health inequities within populations in the country in context of both acute and chronic dental disease. ${ }^{5}$

It is worthwhile to assess again the ability of the dental workforce in India in providing adequate and efficient dental care to a population that is growing in size and diversity. The new look at workforce issues should aim to develop a flexible strategy to steward the human resources of the dental profession. The objective of this review was to assess the status of socioeconomic inequalities of public health dentistry in India, which was conducted by collecting available documents from reviewing articles from various journals, and to review the extent of dental health burden, and to assess its impact on the existing health inequity in India. ${ }^{5}$

\section{Oral Health Care Expenditure}

The irony of the budget allocation in India is that, out of the total budget, the amount that is dedicated to health expenditure is very meagre, and out of this amount only a minute percentage is allocated for oral health related activities. In fact, there is no specific separate allocation for oral health in the Indian budget. India allocated only 4.9 percent of the gross domestic product (GDP) or gross domestic income (GDI) for health related expenditures in the last financial year, whereas other smaller Southeast Asian countries with smaller populations allocate nearly the same amount or more for health-related activities. ${ }^{6}$

\section{Oral health inequity and issues of the Dental Workforce in India}

One of the key factors contributing to oral health inequity is lopsided Dental Care workforce planning in India

\subsection{Deficient Manpower Planning and Projection:}

Until 1966, all the dental colleges in India were government-aided. In that year, the first dental college in the private sector was established. Forecasts of shortages of manpower led to an increase in the number of colleges, especially in the private sector. Private colleges started admitting students under the capitation plan .Like a bull market, the mood was buoyant, expansion frenetic, and expectations high. There was a mushroomlike growth of these private colleges. On the other hand, there has been stagnation in the growth of government colleges, probably due to decrease of the funds provided by the government for the health sector. At present there are nearly four times as many private colleges as government colleges. In tune with the increase in number of dental colleges, there has been a steady increase in the number of dental graduates from the 1950s when there were only a few dental colleges in India. To cope with such an enormous number of dentists graduating each year will require a massive infrastructure, a factor that requires the very urgent attention of all concerned.

4.2. Geographic Imbalance: The number of colleges has increased to meet the demands of the society, but there has been a non uniform growth of these colleges across the country. There is a massive flow in the geographic distribution of the colleges. ${ }^{6}$

4.3. Inadequate Workforce in Rural Areas: Dentistry faces serious problems regarding accessibility of its services to all. In many developing countries like India, oral health services are offered by dentists, who practice in the cities and treat the affluent parts of the urban population. It is often difficult for the poor urban and the rural population to get access to emergency care.

The major missing link causing this unfortunate situation is the absence of a primary health care approach in dentistry. When the primary health care systems were implemented in the 1980 s, dentistry was not adequately included. This has left oral health far behind other health services. The costs of providing services are high compared to other areas of health care, and the workforce is very limited. A common way of thinking among local planners is to increase the number of dentists to meet the workforce problem. They ignore the primary health care approach for oral health services, which can be executed by dental auxiliaries. ${ }^{6}$

\section{Role of Women in the Dental Workforce}

Women's participation in workforce in India has always been considered a step behind their male counterparts. But, women are making inroads in the field of dentistry. Time has come to remove the notion that females lag behind males. India has a comparatively low female to male ratio in the general population as compared to the Western countries and also a few Southeast Asian countries. The ratio in India is 933 women to 1000 males, whereas in Pakistan it is 938 and in China it is 944. The percentage of women in the Indian 
population who are engaged in some kind of work is low (24\%), although that is higher than in Pakistan where $10 \%$ of the female population are working.

The expansion of the number of women in dentistry has been one of the major dental workforce trends during the last quarter of the past century and will continue during the initial decades of this century. This is reflected in the greater number of female than male applicants to dental schools. ${ }^{6,7,8}$

\section{Private Oral Healthcare and health Inequality}

The growth of private oral healthcare sector has been largely seen as a boon, however it adds to everincreasing health inequity. The dominance of the private Sector not only denies access to poorer sections of society, but also skews the balance towards urban-biased, tertiary level health services with profitability overriding equality, and rationality of care often taking a back seat. The increasing cost of oral healthcare that is paid as 'out of pocket' payments is making oral healthcare unaffordable for a growing number of people.

One in three people who need hospitalization and are paying out of pocket are forced to borrow money or sell assets to cover expenses. Over 20 million Indians are pushed below the poverty line every year because of the effect of out of pocket spending on health care. In the absence of an effective regulatory authority over the private healthcare sector the quality of medical care is constantly deteriorating. The services offered at a very high price are excellent but are unaffordable for a common man. This re-emphasizes the role socio-economic inequality plays in healthcare delivery. ${ }^{6}$

\section{Changing Oral Disease Patterns and Treatment Needs and increasing health inequity}

With increasing awareness and advancements, there has been a decline in certain diseases in urban areas or developed areas. To cope with these changes, the workforce should be equipped and capable of satisfying the changing demands and needs of the society.

The two most prevalent diseases are dental caries and periodontal diseases, followed by malocclusion and oral cancers. The potential disease levels have remained high over the years. Moreover, about 40-50 percent of children have malocclusion, and 40 percent of all cancers reported in India are oral cancers Because of the changing disease patterns, the dental sector is going through a transition from a service mix that has been predominantly therapeutic to a service mix that will be mostly preventive.

People across the world are becoming more knowledgeable about dental health. As the population has become more affluent and educated, the value placed on oral health has increased. In addition, the desire for aesthetic dentistry has grown and will probably continue to do so. There has been an increased demand for treatment of periodontal disease, endodontics, dental implants, cosmetic surgery, and adult orthodontics, among others. Changes of this magnitude will have profound effects by reducing the demand for some services and enhancing the demand for others. The workforce should be able to sustain and satisfy the demands ${ }^{6}$

\section{Barriers in Oral Health Promotion}

During the implementation of the National Oral Health Care Programme in the pilot phase, it was perceived that most of the times our policymakers give oral health last priority. ${ }^{9}$ They are inadequately informed about burden of oro-dental problems and its connection with the systemic health and possibly minimal threat to human life due to oro-dental problems makes step motherly treatment for dental public health programmes.

One of the major disadvantages is that in India, health is a state subject and most of the states in the country are suffering from financial burden even for subsistence rather than providing quality health care. Mostly the health care is looked after by the private sector and individual practices including non-formal medical facilities. However, the treatment cost for oral diseases is enormously expensive and it has not been possible for anyGovt. setup to provide dental services to all. The dental graduates are unable to perceive the importance of learning prevention of orodental problems for the community and they are not aware of their responsibilities towards the society. ${ }^{5}$

The internship programme is also underutilized by the dental colleges for services to the grass root level and dental health needs of our geriatric population are overlooked. We do not have organized school oral health education programmes so that children may learn right oral health practices from the beginning. Over and above fastest growing population, rapid westernization and lack of resources are increasing the burden of oral diseases in our country.

\section{Recommendations}

- Reduce income differentials and poverty through progressive taxation and the provision of adequate income support for those in poverty.

- Reduce unemployment through labour market policies that strengthen the position of those at greater risk of unemployment 
- Implement community development programme and behavioural strategies for the disadvantaged population

- Reducing the barriers to regular dental attendance and promoting regular dental attendance for lowsocio-economic groups may reduce oral health inequalities to some extent.

- High risk groups should be identified among the underprivileged for targeted dental health education efforts and delivery of more intensive dental care services

- 6. Appropriate oral health information from an early age within a compulsory school education

- Program appears necessary to enhance health literacy and lessen inequalities in dental health.

- Improving access to health care be a part of global fight against poverty and the reduction of social inequalities

- Reducing racial/ethnic dental health disparities which are mostly socioeconomically driven requires polices that recognize the multilevel pathways underlying them

\section{Conclusion}

It seems it is important to act now to strengthen dental health policy and planning. Up-to-date oral health data are rarely available at national level. A national oral health policy developed as a result of the processes will be both new and innovative, with the best chance of making real, sustainable improvements in the oral health of the population. A national dental health policy must ensure there is an effective monitoring system in place so you can recognize problems as they occur and find solutions for them. To provide adequate, respectable, and attractive

Employment opportunities to the workforce while maintaining a balanced geographical distribution is the main challenge and the root of all the issues facing the dental profession in India. To cope with number of dentists graduating each year will require a massive infrastructure, a factor that requires the very urgent attention. This vicious cycle has to be stopped to get at the root of the problem and begin providing sufficient employment opportunities in an equitable manner. Effects of dental health burden induce health inequality on health of a society are profound. In a large, overpopulated country like India with its complex social structure and economic extremes, the effect of inequity on health system is multifold. Unequal distribution of resources is a reflection of this inequality and adversely affects the health of underprivileged population. The socially underprivileged population groups are unable to access the oral healthcare due to geographical, social, economic or gender related distances.

\section{References}

[1]. Parkash H Shah N. National Oral Health Care Programme: Implementation Strategies. Directorate General of Health Services, Ministry of Health and Family Welfare, Govt. of India, New Delhi. 2000

[2]. Pan American Health Organization. Principles and basic concepts of equity and health. Washington: Pan American Health Organization, HDP Health Equity Interprogrammatic Group, Division of Health and Human Development; 1999.

[3]. MilindDeogaonkar Socio-economic inequality and its effect on healthcare delivery in India: Inequality and healthcare, Electronic Journal of Sociology (2004).

[4]. Ahluwalia MS. Economic performance of states in post-reforms period. Economic and Political weekly, May 62000,1648

[5]. Parkash H, Duggal R, Mathur V P.Final report and recommendations "Formulation of Guidelines for Meaningful and Effective Utilization of Available Manpower at Dental Colleges for Primary Prevention of Oro-dental Problems in the Country". A GOIWHO Collaborative Programme.2007.New Delhi

[6]. ShobhaTandon.Challenges to the Oral Health Workforce in India Journal of Dental Education, Volume 68, Number 7 Supplement; July 2004, 28-33

[7]. National Sample Survey Organization. Department of Statistics. GOI. 42nd and $52^{\text {nd }}$ Round.

[8]. Kaplan G Pamuk E Lynch JW Cohen RD Inequality in income and mortality in the United States: Analysis of mortality and potential pathways. BMJ, 1996, 312,996-1103.

[9]. Parkash H, Shah N. National Oral Health Care Programme: Implementation Strategies. New Delhi: National Oral Health Care Programme, Govt. of India; 2001.

[10]. Gwatkin DR. Poverty and inequalities in health within developing countries: filling the information gap. In: Leon D, Walt G, editors. Poverty, inequality and health - an international perspective. London: Oxford University Press; 2000.

[11]. Parkash H, Duggal R, Mathur V P.Final report and recommendations "Formulation of Guidelines for Meaningful and Effective Utilization of Available

[12]. Mudur G. Inadequate regulations undermine India's healthcare. BMJ 2004; 328,124. 